\title{
A Clinical Analysis of patients seen in a Geriatric Mental Health Camp organized in Mumbai
}

\author{
Akshay Chordia ${ }^{1}$, Sagar Karia ${ }^{2}$, Reetika Dikshit ${ }^{3}$, Nilesh Shah ${ }^{4}$, Heena Merchant ${ }^{5}$, \\ Avinash De Sousa ${ }^{6}$ \\ ${ }^{1}$ Resident Doctor, ${ }^{2,3}$ Assistant Professor, ${ }^{4}$ Professor and Head, ${ }^{5}$ Associate Professor, ${ }^{6}$ Research Associate, \\ Department of Psychiatry, Lokmanya Tilak Municipal Medical College, Mumbai. \\ Corresponding author: Avinash De Sousa \\ Email: avinashdes888@gmail.com
}

\begin{abstract}
Background: Geriatric mental health is a neglected domain of mental health and many cases remain undetected in the community. Community programs have often helped to detect many cases of the elderly with psychiatric problems and help them access care. The current paper aims to present an analysis of patients seen in a geriatric health camp from a psychiatric perspective.

Methods: 103 elderly attended the geriatric camp and were assessed clinically for psychiatric problems. They were also administered the Adenbrooke's Cognitive Examination Revised (ACE-R) Hindi version, Barthel's Index for Activities of Daily Living and 3.Hwalek-Sengstock Elder Abuse Screening Test (H-S/EAST). The results were analyzed statistically and presented.

Results: The mean age of the subjects in the study was $66.05 \pm 7.9$ years. 83 subjects (79\%) out of the 105 were female. The mean BIADL score of the sample was $19.52 \pm 1.9$ and on the basis of scores on the ACE$R$ they were classified as having cognitive impairment $(n=67)$ and not having cognitive impairment $(n=27)$. The cognitively impaired group differed from the non-cognitive impairment on all subscales of the ACE-R. $55(52.4 \%)$ reported the presence of elder abuse but had taken no action against it. The BIADL scores showed a significant correlation on all aspects of ACE-R scores.

Conclusions: Geriatric health camps can serve as a useful arena for the detection of geriatric mental health problems. Further studies in larger populations are needed to corroborate the findings seen in the geriatric health camp reported in this study.
\end{abstract}

Key words: geriatric health, geriatric mental health, ADL, ACE-R

(Paper received $-9^{\text {th }}$ May 2019, Peer review completed $-20^{\text {th }}$ June 2019)

(Accepted $-26^{\text {th }}$ June 2019)

\section{INTRODUCTION}

Geriatric mental health is one of the most neglected domains of mental health care and there are a large number of challenges that come up when one looks at the implementation of mental health care for the elderly [1]. There is a need for mental health screening of the elderly in primary care settings and appropriate referrals when psychopathology is detected [2]. There have been reports in scientific literature of the success of geriatric health camps where psychiatry has been included and has been instrumental in detecting psychiatric problems in the elderly especially when access to mental health care is sparse and far fetched [3]. Forgetfulness is very often the first sign of memory loss or impending dementia and is a symptom that is considered a part of normal aging and is hence never investigated further [4]. This symptom may be a part of medical conditions as well as dementia and also may present as the main symptom in geriatric depression [5]. Another problem with a high prevalence but rarely asked about in clinical settings is elder abuse [6]. Many elders fear reporting abuse as they are dependent on their caregivers and the problem goes undetected 
and under-reported [7]. Psychiatric care for the elderly must be community based so that patients have access to care and the stigma of receiving psychiatric care is reduced [8]. In fact efforts must be made to have screening for mental health problems in community based camps where the elderly come for medical checks and psychiatric problems may be detected and treated simultaneously [9]. Keeping this in mind, we participated in a medical geriatric camp for the elderly and herewith present a clinical analysis of the patients seen at such a camp organized in Mumbai.

\section{METHODOLOGY}

A free medical camp was organized by local non-governmental organizations in the Sion area of Mumbai which has a large number of slum dwellings. The department of Psychiatry participated in this camp for mental health awareness and screening for psychiatric problems in the elderly as we form part of a major tertiary general hospital in the area. 105 patients attended the camp from different areas of Mumbai. All were in the geriatric age group above the age of 60 years. Of these only 94 completed all the scales and were included in the final study analysis. They were screened for psychopathology via a history and clinical mental status evaluation like done in a routine out patient setting. They were diagnosed with a psychiatric disorder if present, memory loss and questioned about elder abuse.

They were also assessed using the following scales -

- Adenbrooke's Cognitive Examination Revised (ACE-R) (Hindi version) - The Addenbrooke's Cognitive Examination is a brief, 15-20-minute test battery originally designed to detect and classify different kinds of dementia without the use of specialized test equipment [10]. It incorporates the Mini Mental Status Examination (MMSE) [11], with additional memory, language, and visuospatial components. The maximum score is 100, weighed as follows: orientation (10), attention (8), memory (35), verbal fluency (14), language (28), and visuospatial ability (5).

- Barthel's Index of Activities of Daily Living (BIADL) - This is a standardized scale widely used by clinicians and researchers to assess disability [12]. It includes 10 fundamental items of activities of daily living (ADL) viz. feeding, grooming, bathing, dressing, bowel and bladder care, toilet use, ambulation, transfers, and stair climbing. The total score ranges from 0 to 20 , with higher scores signifying better degrees of function. Many researchers in different populations have demonstrated the $\mathrm{BI}$ to be reliable and valid [13-14].

- Hwalek-Sengstock Elder Abuse Screening Test (H-S/EAST) - The scale was developed to identify indicators and actual symptoms of elder abuse using a pool of over a thousand items selected from various elder-abuse protocols. Identifying the correlates of abuse were of most interest in the development of a screening tool, because they could be present prior to abuse occurring. This original pool of items was subjected to data reduction techniques to develop a brief screening tool. It has been widely used in the screening for elder abuse [15].

The study was approved in a Departmental Review Board meeting and informed and written valid consent was taken prior to administering the scales. The data was statistically analyzed using descriptive statistics for the sociodemographic data. The ACE scores between groups having and not having cognitive impairment was analyzed using the unpaired t test and correlations between ACE-R and BIADL was established using Pearson's correlation. All the statistical calculations were done using the Graph Pad Statistical Software online.

\section{RESULTS}

The mean age of the subjects in the study was $66.05 \pm 7.9$ years. 83 subjects $(79 \%)$ out of the 105 were female. Majority of subjects i.e. 94 (89.5\%) were Hindus while 61 (58.1\%) belonged to nuclear families. The socio-demographic data has been described in Table 1. The mean BIADL score of the sample was $19.52 \pm$ 
1.9 and on the basis of scores on the ACE-R they were classified as having cognitive impairment and not having cognitive impairment. This was based on the cut off score of 88 on the ACE-R. The cognitively impaired group differed from the non-cognitive impairment on all subscales of the ACE-R (Table 2). On elder abuse screening 55 (52.4\%) reported the presence of elder abuse but had taken no action against it. The BIADL scores showed a significant correlation on all aspects of ACE-R scores and has been documented in Table 3.

Table 1 - Socio-demographic data of the sample

\begin{tabular}{|c|c|}
\hline Socio demographic parameter & Mean / N \\
\hline Age & $66.05 \pm 7.9$ years \\
\hline Gender & \\
\hline Male & $22(21)$ \\
\hline Female & $83(79)$ \\
\hline Family Type & \\
\hline Nuclear & $61(58.1)$ \\
\hline Joint & 44 (41.9) \\
\hline Religion & \\
\hline Hindus & $94(89.5)$ \\
\hline Muslims & $11(10.5)$ \\
\hline Education (in years) & \\
\hline Uneducated & $23(21.9)$ \\
\hline $1-5$ years & $5(4.8)$ \\
\hline $6-9$ years & $21(20)$ \\
\hline $10-12$ years & $30(28.6)$ \\
\hline$>12$ years & $26(24.7)$ \\
\hline Marital Status & \\
\hline Married & $58(55.2)$ \\
\hline Single & $7(6.7)$ \\
\hline Separated & $3(2.9)$ \\
\hline Widow & $37(35.2)$ \\
\hline Income Status & \\
\hline Dependent & $77(73.3)$ \\
\hline Independent & $28(26.7)$ \\
\hline Psychiatric Illness & \\
\hline No psychiatric illness & $73(69.5)$ \\
\hline Depression & $28(26.7)$ \\
\hline Schizophrenia & $1(0.9)$ \\
\hline Dementia & $1(0.9)$ \\
\hline Insomnia & $1(0.9)$ \\
\hline Alcohol Use Disorder & $1(0.9)$ \\
\hline Medical Illness & \\
\hline Diabetes & $22(21)$ \\
\hline Hypertension & $58(55.2)$ \\
\hline Cerebrovascular event & $2(1.9)$ \\
\hline
\end{tabular}

\section{DISCUSSION}

The present study just looks at preliminary data from a health camp conducted for the elderly but some very interesting facts emerge. $71.3 \%$ (67) subjects attending the camp had cognitive impairment and had never sought any help for the same. This indicates that while cognitive impairment may be widely prevalent in the elderly they rarely seek help for the same and unless they are examined for the same it may go undetected and untreated [16]. Thus many cases of age associated impairment could receive treatment early and the 
progression to dementia may be halted if more elderly come for help the moment the cognitive impairment ensues [17]. It was interesting to note that cognitive impairment was uniform across all domains of the ACE$\mathrm{R}$ and no specific pattern of cognitive impairment emerged.

Table 2 - Scores on ACE-R scale

\begin{tabular}{|c|c|c|c|c|}
\hline $\begin{array}{c}\text { ACE-R Scores Domain } \\
(\mathbf{N}=94)\end{array}$ & Present (N=67) & Absent $\mathbf{( N = 2 7 )}$ & t value & p value \\
\hline ACE total & $69.48 \pm 20.03$ & $92.81 \pm 4.15$ & 5.98 & $0.0001^{*}$ \\
\hline ACE-attention & $15.24 \pm 4.06$ & $17.85 \pm 0.45$ & 3.32 & $0.0013^{*}$ \\
\hline ACE-memory & $14.58 \pm 6.8$ & $23.74 \pm 2.2$ & 6.83 & $0.0001^{*}$ \\
\hline ACE-fluency & $6.27 \pm 3.12$ & $10.96 \pm 2.59$ & 6.91 & $0.0001^{*}$ \\
\hline ACE-Language & $22.46 \pm 6.11$ & $26.00 \pm 0.0$ & 2.99 & $0.003^{*}$ \\
\hline ACE-visuospatial & $10.88 \pm 4.38$ & $14.30 \pm 2.31$ & 3.82 & $0.008^{*}$ \\
\hline
\end{tabular}

${ }^{*}$ significant $(\mathrm{p}<0.05)$. All calculations done using unpaired $t$ test

Table 3 - Correlation between ACE-R Scores and BIADL scores

\begin{tabular}{|c|c|c|c|c|c|c|}
\hline & $\begin{array}{c}\text { ACE-R } \\
\text { Total }\end{array}$ & $\begin{array}{c}\text { ACE-R } \\
\text { attention }\end{array}$ & $\begin{array}{l}\text { ACE-R } \\
\text { memory }\end{array}$ & $\begin{array}{l}\text { ACE-R } \\
\text { fluency }\end{array}$ & $\begin{array}{c}\text { ACE-R } \\
\text { language }\end{array}$ & $\begin{array}{c}\text { ACE-R } \\
\text { visuospatial }\end{array}$ \\
\hline $\begin{array}{l}\text { Barthel's } \\
\text { Score } \\
(\mathrm{N}=94)\end{array}$ & $\begin{array}{c}r=0.496 \\
p<0.0001^{*}\end{array}$ & $\begin{array}{c}r=0.520 \\
p<0.0001^{*}\end{array}$ & $\begin{array}{c}r=0.335 \\
p=0.009^{*}\end{array}$ & $\begin{array}{c}r=0.279 \\
p=0.006^{*}\end{array}$ & $\begin{array}{c}r=0.550 \\
p<0.0001^{*}\end{array}$ & $\begin{array}{c}r=0.401 \\
\mathrm{p}<0.0001^{*}\end{array}$ \\
\hline
\end{tabular}

*significant $(\mathrm{p}<0.05)$. All calculations done using Pearson's Correlation

Many of the subjects in the study did very well in activities of daily living. Many elderly in India continue to do their ADL unless crippled with physical difficulties even though they may have mild to moderate cognitive impairment [18]. 52.4\% (55) subjects in the study reported elder abuse. Elder abuse studies using community cohorts are lacking in India and the prevalence of elder abuse is in fact quite high and it goes unreported [19]. All the elderly in our sample considered elder abuse in some way to not be problem and did not want to report the same as they were completely dependent on their children. This is in keeping with studies that were done previously [20]. The current study was circumscribed and cross sectional while being limited to an urban cohort that attended a geriatric health camp. Further studies in larger samples would be needed to corroborate and give impetus to our findings. There is a need for larger epidemiological surveys to understand the extent to which geriatric mental health problems are neglected and remains undetected in these populations.

\section{REFERENCES}

1. Lodha P, De Sousa A. Geriatric mental health: the challenges for India. J Geriatr Ment Health 2018;5(1):16-29.

2. Seby K, Chaudhury S, Chakraborty R. Prevalence of psychiatric and physical morbidity in an urban geriatric population. Indian J Psychiatry 2011;53(2):121-7.

3. Tiwari SC, Srivastava G, Tripathi RK, Pandey NM, Agarwal GG, Pandey S, Tiwari S. Prevalence of psychiatric morbidity amongst the community dwelling rural older adults in northern India. Indian J Med Res 2013;138(4):504-14.

4. Ballard J. Forgetfulness and older adults: concept analysis. J Adv Nurs 2010;66(6):1409-19.

5. Manthorpe J, Samsi K, Campbell S, Abley C, Keady J, Bond J, Watts S, Robinson L, Warner J, Iliffe S. From forgetfulness to dementia: clinical and commissioning implications of diagnostic experiences. $\mathrm{Br} \mathrm{J}$ Gen Pract 2013;63(606):e69-75.

6. Chokkanathan S, Lee AE. Elder mistreatment in urban India: a community based study. J Elder Abuse Negl 2006;17(2):45-61. 
7. Skirbekk V, James KS. Abuse against elderly in India-The role of education. BMC Public Health 2014;14(1):336.

8. de Mendonça Lima CA, Levav I, Jacobsson L, Rutz W. Stigma and discrimination against older people with mental disorders in Europe. Int J Geriatr Psychiatry 2003;18(8):679-82.

9. Ingle GK, Nath A. Geriatric health in India: Concerns and solutions. Indian J Commun Med 2008;33(4):214-8.

10. Mioshi E, Dawson K, Mitchell J, Arnold R, Hodges JR. The Addenbrooke's Cognitive Examination Revised (ACE- R): a brief cognitive test battery for dementia screening. Int J Geriatr Psychiatry 2006;21(11):1078-85.

11. Folstein MF, Folstein SE, McHugh PR. "Mini-mental state": a practical method for grading the cognitive state of patients for the clinician. J Psychiatr Res 1975;12(3):189-98.

12. Collin C, Wade DT, Davies S, Horne V. The Barthel ADL Index: a reliability study. Int Disabil Stud 1988;10(2):61-3.

13. Sinoff G, Ore L. The Barthel Activities of Daily Living Index: self- reporting versus actual performance in the old- old ( $\geq 75$ years). J Am Geriatr Soc 1997;45(7):832-6.

14. Wade DT, Collin C. The Barthel ADL Index: a standard measure of physical disability?. Int Disabil Stud 1988;10(2):64-7.

15. Neale AV, Hwalek MA, Scott RO, Sengstock MC, Stahl C. Validation of the Hwalek-Sengstock Elder Abuse screening test. J Appl Gerontol 1991;10(4):406-18.

16. Middleton LE, Barnes DE, Lui LY, Yaffe K. Physical activity over the life course and its association with cognitive performance and impairment in old age. J Amer Geriatr Soc 2010;58(7):1322-6.

17. Deary IJ, Corley J, Gow AJ, Harris SE, Houlihan LM, Marioni RE, Penke L, Rafnsson SB, Starr JM. Age-associated cognitive decline. Br Med Bull 2009;92(1):135-52.

18. Perneczky R, Pohl C, Sorg C, Hartmann J, Komossa K, Alexopoulos P, Wagenpfeil S, Kurz A. Complex activities of daily living in mild cognitive impairment: conceptual and diagnostic issues. Age Ageing 2006;35(3):240-5.

19. Mawar S, Koul P, Das S, Gupta S. Association of physical problems and depression with elder abuse in an urban community of North India. J Geriatr Ment Health 2018;43(3):165-9.

20. Grover S. Elder abuse: the need for awareness. J Geriatr Ment Health 2015;2(2):65-7.

Acknowledgements - Ni

Conflict of Interest - Nil

Funding - Nil 